\title{
Bacterial Adhesion and Biofilm Formation on Direct, Tooth-Colored Restorative Materials: An in vitro Study
}

\author{
Nathaniel Denson ${ }^{1}$, Martha Wells ${ }^{1}$, David A Tipton ${ }^{2}$, Franklin Garcia Godoy ${ }^{2}$ and Jegdish P Babu ${ }^{2 *}$ \\ ${ }^{1}$ Department of Pediatric Dentistry, University of TN Health Science Center, USA
}

${ }^{2}$ Department of Bioscience Research, University of TN Health Science Center, USA

Submission:March 30, 2018 ; Published: April 11, 2018

*Corresponding author: Jegdish P Babu, Professor, Department of Bioscience Research, College of Dentistry, University of TN Health Science Center, Memphis, TN, USA, Tel: (901)4484342; Email: Jbabu@uthsc.edu

\begin{abstract}
Dental restorative materials are routinely used to restore carious lesions, but over time, they may fail, leading to secondary dental caries. The longevity of restorations appears to depend upon their resistance to bacterial adhesion and biofilm formation.

Objective: To investigate susceptibility of four restorative composite materials to bacterial colonization and biofilm formation.

Methods: 20 circular discs $(8 \mathrm{x} 2 \mathrm{~mm})$ of four restorative materials, Esthet-X ${ }^{\circledR}$ HD (Dentslpy), Filtek ${ }^{\mathrm{TM}}$ Bulk Fill (3M ESPE), Fuji II® LC (GC America), and Activa ${ }^{\mathrm{TM}}$ BioActive-Restorative ${ }^{\mathrm{TM}}$ (PulpDent) were prepared and de-contaminated. Streptococcus mutans ATCC 700610, and mixed bacterial oral plaque, were cultured for $24 \mathrm{~h}$, and bacteria were suspended to $1 \times 107$ cells $/ \mathrm{ml}$. For adhesion assays, quadruplicate composite discs were incubated with one $\mathrm{ml} S$. mutans for $24 \mathrm{~h}$. Biofilms of $S$. mutans and mixed bacterial plaque were grown on quadruplicate discs by inoculating them with one $\mathrm{ml}$ of bacterial suspension and incubated for 3 weeks. In both assays the bacterial number on each disc was determined by MTT assay.
\end{abstract}

Results: Fuji and Activa had greater percentages of adherent bacteria (22.8 \pm 3.9 and $18.94 \pm 4.7$, respectively) than Esthet-X (8.12 \pm 1.22$)$ and Filtek $(5.6 \pm 0.94)(\mathrm{p}<0.03)$. Both Fuji and Activa also supported significantly greater $(\mathrm{p}<0.002)$ biofilm growth than Esthet-X and Filtek.

Conclusions: Composite materials appear to differ in their ability to facilitate bacterial adhesion and biofilm formation. The differences in bacterial biofilm formation and retention on the surfaces of the restorative materials demonstrated in this study may be helpful to dentists in selecting restorative composite materials for dental restorations.

Keywords: Dental restorations; Biofilm; Bacterial adhesion; Streptococcus mutans; Plaque bacteria; Secondary caries

\section{Introduction}

A permanent, esthetic restorative material that could be placed directly in the mouth to restore cavities in teeth has long been an important contribution in restorative dentistry and oral health. In fact, the uses of direct esthetic restorations have overtaken amalgam, becoming the most common treatment for minimally invasive dental procedures [1]. These esthetic composite materials can be placed as temporary, intermediate, or permanent restorations [2]. However, the term "permanent restoration" can be deceiving, as no dental restoration is truly permanent. Restorations have a limited lifespan which is primarily based on the material used, although other factors contribute to failure such as individual's age, oral hygiene and risk of caries as well as the skill of the dentist placing technique-sensitive materials [2,3].

One of the primary causes of failure of a composite restoration is secondary or recurrent caries. Recurrent caries occurs when a restoration leaks and allows the formation of a cavity beneath the existing restoration. This process requires a susceptible restoration along with bacterial adhesion and accumulation. Different restorative materials have properties such as surface roughness and antibacterial components that modulate this process. However, previous in vitro research has shown that demineralization depth and degradation of the restorative material is bacteria-dependent. Restoration longevity, therefore, is linked to susceptibility towards bacterial colonization [4-6].

Bacterial colonization in the mouth leads to the creation of a biofilm. The formation of superficial biofilm on a dental surface is a complex phenomenon and different key factors are involved [7]. First, formation of salivary pellicle on the biomaterial by adsorption of host saliva proteins [8]. The next step involves the adhesion of the microbial cells, when bacteria begin to anchor. At 
this stage, the colonization of the surface takes place, as described by Hannig [9]. This adhesion of the bacteria to the salivary pellicle is critical for plaque formation [10]. In the plaque, minimal numbers of specific bacteria must be present for the cariogenic process to occur [5]. It is not certain how much of a role the restorative material plays, but different studies suggest that several materials may have antibacterial activity or may even induce the growth of several bacteria [11]. Evidence show that there is a need for development of alternative resins that do not enhance bacterial growth leading to secondary caries and restorative failure, and the need to evaluate biofilm formation on the new resins [12].

Despite numerous studies on the morphology of oral biofilms only limited information is available on bacterial adhesion, especially on the surface of new restorative materials. Still less is known about bacterial adherence on new bioactive materials which have recently been proposed as restorative materials with enhanced biological, physical and mechanical properties compared to traditional composites $[13,14]$. There is also little information on bacterial adhesion to restorative materials after application of a salivary pellicle. This is essential to mimic the oral environment, as previous research shows that presence of a human salivary pellicle significantly affects biofilm formation on many types of restorative materials [4,15-17].

Restorative materials are susceptible to bacterial biofilm formation, and this affects the integrity of the materials and ultimately oral health. Biofilm formation appears to be influenced by hydrophobic and hydrophilic interactions between the bacteria and the restorative material surfaces. Additionally, restorative material's chemical composition and surface smoothness also play roles in biofilm formation [18]. The aim of this study was to evaluate Streptococcus mutans and mixed bacterial plaque bacterial biofilm formation on four different unpolished restorative materials following the application of a salivary pellicle. The major bacteria species in areas of carious lesions are different from those in areas without caries [13]. In this study, cariogenic bacteria, $S$. mutans and the mixed bacterial plaque which represent the average human oral flora, were employed to test for adhesion and biofilm formation by these microorganisms on the restorative materials, Fuji II LC, Esthet-x HD, Filtek Bulk Fill, and Activa BioActive.

The hypothesis tested in the present study was that differences in the chemical nature and morphological properties of dental restorative materials affect the formation of microbial biofilms on them, and that some materials may actually promote bacterial accumulation.

\section{Materials and Method}

\section{Preparation of restorative material discs}

The four restorative materials, Fuji II LC (GC Corporation, Tokyo, Japan), Esthet-x HD (Dentsply Caulk, Milford, DE), Filtek Bulk Fill (3M ESPE, St. Paul, MN), and Activa BioActive (PulpDent
Corporation, Watertown, MA) were made into multiple discs. The restorative materials were placed into round metal molds $(8 \mathrm{~mm}$ by $2 \mathrm{~mm}$ ) and light cured for 20 seconds to form discs. The discs were decontaminated by soaking in $70 \%$ ethanol for 10 minutes and placing them under a UV light for 24 hours. The sterility of discs was confirmed by incubating the discs in Todd-Hewitt Broth (THB; Difco, MI, USA) for 24 hours at $37^{\circ} \mathrm{C}$. The discs were rinsed with sterile PBS and then each disc was incubated with $0.5 \mathrm{ml}$ of human clarified, pooled saliva (see below) for 24 hours. The salivacoated discs were rinsed with PBS and then used in the study.

\section{Collection of saliva}

Paraffin stimulated whole human saliva (Protocol approved by the University IRB) was collected from a single laboratory individual in a cup placed in ice. The saliva was then centrifuged $(8,000 \mathrm{xg})$ for $10 \mathrm{~min}$, and then the supernatant was collected and kept frozen until needed for the study.

\section{Bacterial adhesion assay}

Streptococcus mutans 700610 obtained from ATCC (Rockville, MD) were grown in THB for 24 hours at $37^{\circ} \mathrm{C}$. A standard suspension $(1 \times 107$ cells $/ \mathrm{ml})$ of bacteria was prepared. Five discs prepared from each restorative material were incubated with $1.0 \mathrm{ml}$ of bacterial suspension in a 48 -well culture dish for 24 hours at $37^{\circ} \mathrm{C}$, and then rinsed with PBS to remove the nonadherent bacteria. The discs were then incubated with $0.3 \mathrm{ml}$ of MTT (3-(4,5-dimethylthiazol-2-yl)-2,5-diphenyltetrazolium bromide) labeling reagent (Sigma Aldrich Chemical Co. St. Louis, MO) for 4 hours and then the solubilizing agent supplied by the manufacturer was added and incubated overnight. An aliquot (0.1 $\mathrm{ml}$ ) of supernatant from each disc was placed in a 96-well flat bottom microtiter plate and optical density reading was read at $570 \mathrm{~nm}$ using a BMG Spectrostar spectrophotometer (BMG labtech Inc. Cary, NC). The background absorbance measured at $690 \mathrm{~nm}$ was subtracted. Discs incubated with THB media alone served as negative control. The method is based on the conversion of water soluble MTT compound to an insoluble formazan product. Viable cells with active metabolism convert MTT into formazan, however, dead cells lose this ability. The number of adherent bacteria on each disc was determined by comparing the absorbance value to the values obtained from the standard curve prepared with known bacterial counts.

\section{Biofilm formation on composite discs}

Saliva coated restorative discs were incubated with $1.0 \mathrm{ml}$ of standard suspension of $S$. mutans or with a mixed bacterial plaque sample and incubated for 21 days at $37^{\circ} \mathrm{C}$. During this period, every 48 hours $0.1 \mathrm{ml}$ of supernatant media was discarded and replaced with fresh THB, in order to provide nourishment for the growing biofilm. The dental plaque was obtained from three laboratory individuals (Approved by the University IRB) and pooled. The pooled plaque sample was grown in Todd-Hewitt broth (THB) for 24 hours at $37^{\circ} \mathrm{C}$ and used in the study. Gram- 
stain of the culture revealed both gram positive and gram negative cocci and bacillus. No effort was made to grow the anaerobes from the pooled plaque sample. At the end of 21 days, discs were rinsed with Phosphate Buffered Saline (PBS) to remove un-bound bacteria and the bacterial load on each disc was assessed using the MTT reagent as described above.

\section{Statistical analysis}

All experiments were performed a minimum of three times, with five samples at each time. The data were expressed as the means \pm SD and were analyzed using a one-way ANOVA and Scheffe's F procedure for post hoc comparisons, using STATVIEW@software (SAS Institute, Cary, NC, USA). The significance level adopted was $5 \%(\mathrm{P}<0.05)$.

\section{Results}

\section{Adhesion of $S$. mutans to composite discs}

The saliva-coated composite discs ( 5 from each group) were tested for adhesion of $S$. mutans 700610 by incubating the discs with $1 \times 107$ bacteria/ml for 24 hours at $37^{\circ} \mathrm{C}$ in a 48 -well culture plate. The results (Figure 1) demonstrate the differences in $S$. mutans adherence to the various restorative composite discs. Significantly higher bacterial adhesion was found on the Fuji II LC $(\mathrm{P}<0.026)$, and Activa BioActive discs $(\mathrm{P}<0.031)$ compared to Esthet-X and Filtek Bulk Fill discs. On an average, 18,253 \pm 985 bacteria 15,152 \pm 750 bacteria adhered to Fuji II LC and Activa BioActive composite discs, respectively, while the numbers of bacteria on Esthet-X and Filtek Bulk Fill were 6,495 \pm 495 and $4,793 \pm 440$, respectively (Figure 1 ).

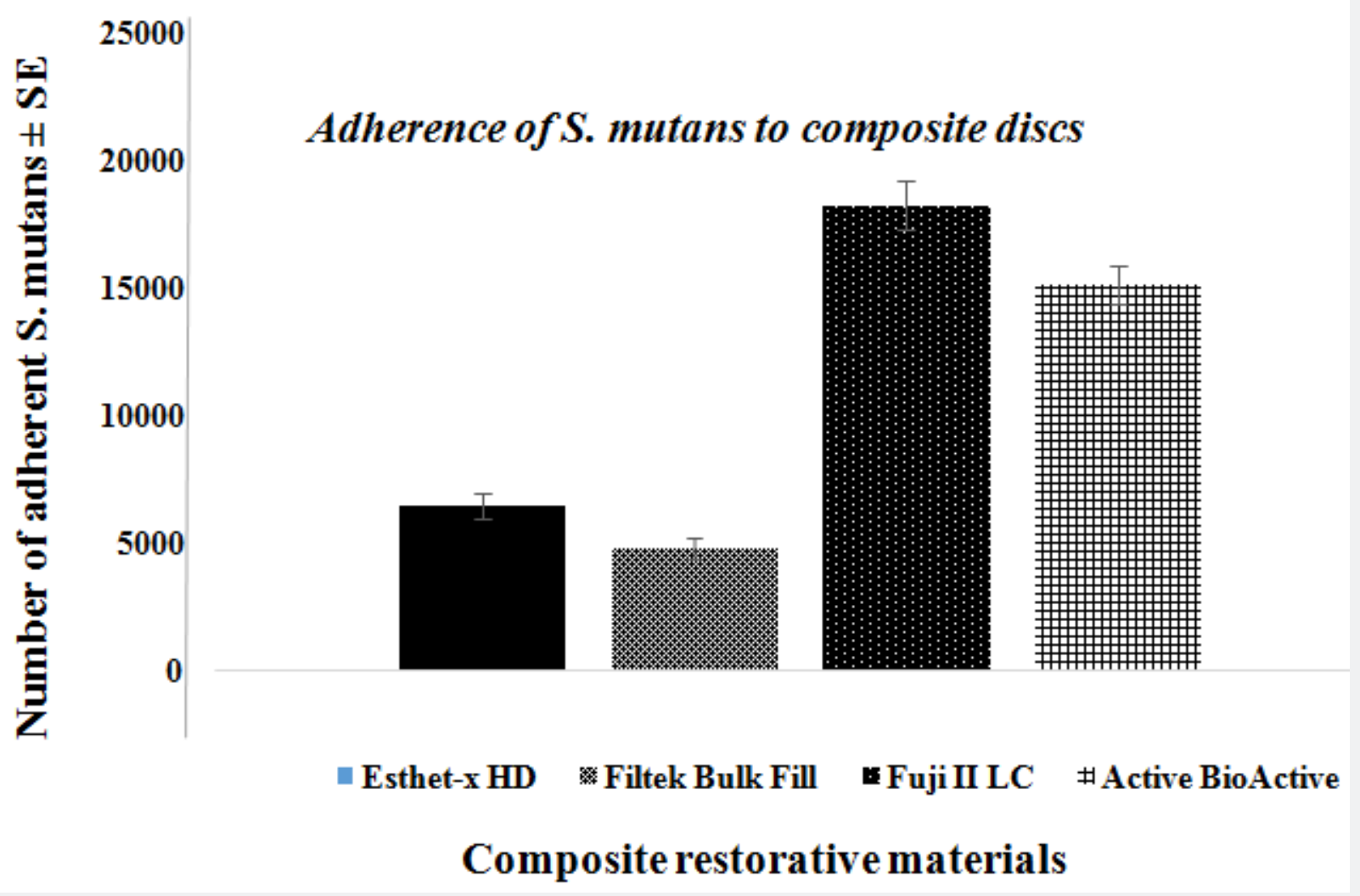

Figure 1: Demonstrates adherence of $S$. mutans to composite material discs. Values represent the (mean $\pm S E$ ) of three independent experiments performed with five sample discs. The number of adherent $S$. mutans to Fuji II LC $(P<0.026)$ and Activa BioActive $(P<0.031)$ composite discs were significantly higher than those adhered to the other two composite discs.

\section{Biofilm formation on composite discs}

Over all higher numbers of tested bacteria of the three week old biofilms were found on all composite discs than the numbers we found in adhesion assay. Three- week biofilm study with $S$. mutans and mixed bacterial plaque also showed results similar to adhesion assay (Figure 2). Significantly higher numbers of $S$. mutans biofilm bacteria were found on Fuji II LC $(24,972 \pm 1,880$; $\mathrm{P}<0.018)$ and Activa BioActive discs $(21,055 \pm 1,650 ; \mathrm{P}<0.026)$ compared to the numbers on Esthet-X $(9,192 \pm 580)$ and Filtek
Bulk Fill $(8,173 \pm 520)$. The mixed plaque biofilm bacterial numbers were higher on all composite discs than the single $S$. mutans. The results (Figure 2) show that on an average 41,065 $\pm 3,750$ bacteria on Activa BioActive, and on Fuji II LC 43,470 \pm 4,955 composite discs, respectively. In comparison, only 12,040 \pm 1,250 and $11,735 \pm 1,250$ bacteria were found on Esthet-X and Filtek Bulk Fill, respectively (Figure 2). The result of this study delineates the differences between composite materials with respect to microbial colonization on their surfaces. 


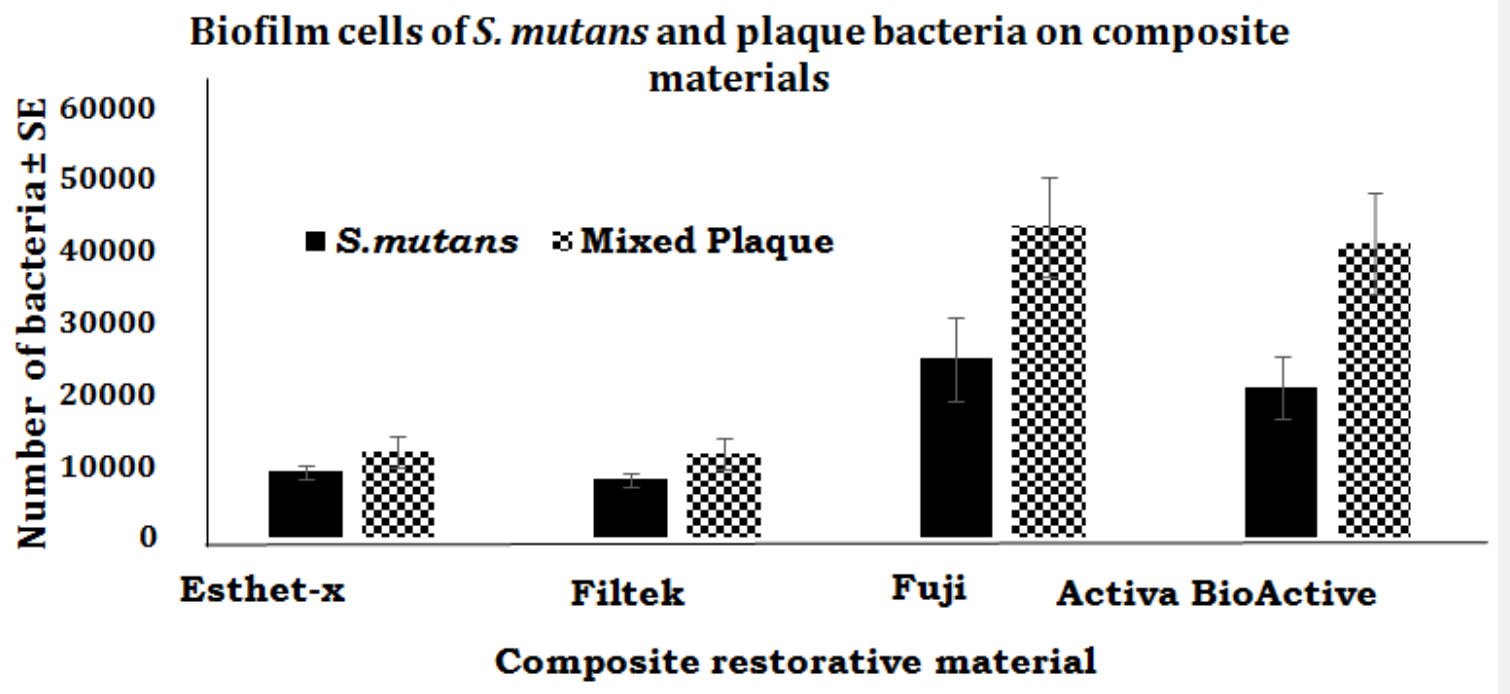

Figure 2: S. mutans and mixed bacterial plaque biofilm (21 days) formed on composite materials tested. Solid bars indicate the $S$. mutans bacterial number after three weeks biofilm formation. The bars with open circles represent the mixed plaque bacteria of the biofilm. Values represent the (mean $\pm \mathrm{SE}$ ) of three independent experiments performed with five sample discs. The number of adherent biofilm bacteria to Fuji II LC $(P<0.018)$ and Activa BioActive $(P<0.026)$ composite discs were significantly higher than those adhered to the other two composite discs.

\section{Discussion}

Several factors have been shown to be important in oral bacterial adhesion and biofilm formation on hard dental surfaces and restorations. Certain restorative composites may have properties that make them more susceptible to dental biofilm formation which can lead to secondary caries and even periodontitis. Various in vitro studies have demonstrated that oral bacteria attachment and biofilm formation occur at a higher frequency on composites than on the natural teeth in the oral cavity $[5,19]$.

Biological interactions of microorganism with dental restorative materials play a crucial role in determining the successful function of these materials. The aim of the present study was to compare the in vitro bacterial adhesion and biofilm formation on four widely used dental restorative materials. Circular un-polished discs were light cured under similar conditions, so that differences in adhesion and biofilm formation would result from the properties and composition of the material itself. The discs were coated with whole human saliva to simulate conditions in the oral cavity. Such experiments were conducted successfully in our laboratory previously [1].

Our results showed lower bacterial adhesion and biofilm formation on Filtek discs followed by Esthet-x discs. Bulk fill composites are newer materials that have limited studies investigating their properties [5], but no studies to the knowledge of the investigators have described biofilm formation on these materials, especially with mixed bacterial plaque organisms. Filtek bulkfil has been shown to have spherical particles ranging from 0.1 to 4.0 micro meters while Esthet-x has particles sizes of approximately 2.5 micro meters. Filler particle and surface roughness has been shown to influence bacterial adhesion with materials with small filler size having lower bacterial adherence. The Fuji and Activa discs harbored the highest bulk of biofilm, and facilitated adhesion of $S$. mutans (Figures $1 \& 2$ ). Less bacterial adhesion to Esthet-x and Filtek discs may be due to the filler size, which is different from that of Fuji and Activa. Fuji II has particle sizes of approximately 5.9 micro meters while Activa is uncharacterized in this regard.

While filler size may be important, these results clearly demonstrate the nature of composite materials plays a role in the microbial bioactive interaction. Other studies have shown that the surface properties of a material, such as hydrophobicity and ion release, influence bacterial adhesion and biofilm formation. Higher numbers of bacteria associated with ionomer-containing restorations were also reported by other investigators [20]. A higher degree of bacterial biofilm formation on the Fuji discs may be due to the positive surface charge of this material, which may facilitate bacterial colonization. Other investigators have shown that more bacteria adhere to positively charged composites [13]. Brambilla et al. [21] showed the same results, that surface charge of the dental material plays a vital role in microbial adhesion. It may also be possible that Fuji and Activa adsorb more salivary receptor molecules than the other two materials tested, however we did not characterize these potential differences in this study.

Within the limitations of this study, our findings demonstrated differences in cariogenic bacteria adhesion and biofilm formation by mixed bacteria obtained from human plaque between four different restoration materials. However, other factors such as surface roughness, and preferential adsorption of salivary 
molecules, which may also affect these processes, were not investigated in this study. If the integrity of the composite is not compromised, then it would be beneficial to choose a restoration which does not favor microbial colonization.

\section{Conclusion}

The study demonstrated the influence of nature and type of dental restorative materials on bacterial colonization by cariogenic and plaque microorganisms. The result of the study highlights the differences between restorative materials and may aid the Dentists in choosing the restorative material which does not favor the microbial colonization, thus preventing the failure of the restorations.

\section{Acknowledgements}

Supported by the UT College of Dentistry Alumni Endowment Fund and the Tennessee Dental Association Foundation

\section{Conflict of Interest}

The authors have no conflict of interest with the manufacturer of products used in the study.

\section{References}

1. Banzi EC, Costa AR, Puppin-Rontani RM, Babu JP, Garcia-Godoy F (2014) Inhibitory Effects of a Cured Antibacterial Bonding System on Viability and Metabolic Activity of Oral Bacteria. Dental Materials 30(9): e238-e244.

2. McCraken MS, Gordan VV, Litaker MS, Funkhouser E, Fellows JL, et al. (2013) A 24-month evaluation of amalgam and resin-based composite restorations: Findings from The National Dental Practice-Based Research Network. J Am Dent Assoc 144(6): 583-593.

3. Demarco FF, Correa MB, Cenci MS, Moreas RR, Opdam NJ (2012) Longevity of posterior composite restorations: not only a matter of materials. Dent Mater 28(1): 87-101.

4. Fronza BM, Ayres A, Pacheco RR, Rueggeberg FA, Dias C, et al. (2017) Characterization of Inorganic Filler Content, Mechanical Properties, and Light Transmission of Bulk-fill Resin Composites. Oper Dent 42(4): 445-455.

5. Montonaro L, Campoccia D, Rizzi S, Donati ME, Breschi L, et al. (2004) Evaluation of bacterial adhesion of Streptococcus mutans on dental restorative materials. Biomaterials 25(18): 4457-4463.

6. Steinberg D (2000) Studying plaque biofilms on various dental surfaces. In: An YH, Friedman RJ, editors. Handbook of bacterial adhesion: principles, methods, and applications, Humana Press, New Jersey, USA, pp. 353-370.
7. Guggenheim B, Gietsen E, Schupbach P, Shapiro S (2001) Validation of an in vitro biofilm model of supra-gingival plaque. J Dent Res 80(1): 363-370.

8. Cazzaniga G, Ottobelli M, Ionescu A, Garcia-Godoy F, Brambilla E (2015) Surface properties of resin-based composite materials and biofilm formation: A review of the current literature. American J of Dentistry 28(6): 311-320.

9. Hannig M (1999) Transmission electron microscopy of early plaque formation on dental materials in vivo. Eur J Oral Sci 107(1): 55-64.

10. Van Houte J (1982) Bacterial Adherence and the dental plaque formation. Infection 10(4): 252-260.

11. Hahn R, Weiger R, Netuschil L, Bruch M (1993) Microbial accumulation and vitality on different restorative materials. Dent Mater 9(5): 312316.

12. Teughels W, Van Assche N, Sliepen I, Quirynen M (2006) Effect of material characteristics and/or surface topography on biofilm development. Clin Oral Implants Res 17 Suppl 2: 68-81.

13. Carlen A, Nikdel K, Wennerberg A, Holmberg K, Olsson J (2001) Surface characteristics and in vitro biofilm formation on glass ionomer and composite resin. Biomaterials 22(5): 481-487.

14. Brambilla E, Cagetti MG, Gagliani M, Fadini L, Garcia-Godoy F, et al. (2005) Influence of Different Adhesive Restorative Materials on Mutans Streptococci Colonization. Am J Dent 18(3): 173-176.

15. Scannapieco FA (1994) Saliva-bacterium interactions in oral microbial ecology. Crit Rev Oral Biol Med 5(3-4): 203-248.

16. Steinberg D, Mor C, Dogan H, Zacks B, Rotstein I (1999) Effect of salivary biofilm on the adherence of oral bacteria to bleached and non-bleached restorative material. Dent Mater 15(1): 14-20.

17. Satou J, Fukunaga A, Morikawa A, Matsumae I, Satou N, et al. (1991) Streptococcal adherence to uncoated and saliva-coated restoratives. J Oral Rehabil 18(5): 421-429.

18. Marsh PD (2006) Dental Plaque as a Biofilm and a Microbial Community-Implications for Health and Disease. BMC Oral Health 6 Suppl 1: S14.

19. Eick S, Glockmann E, Brandl B, Pfister W (2004) Adherence of Streptococcus mutans to various restorative materials in a continuous flow system. J Oral Rehab 31(3): 278-285.

20. Fucio SB, Paula AB, Sardi JC, Duque C, Correr-Sobrinho L, et al. (2016) Streptococcus Mutans Biofilm Influences on the Antimicrobial Properties of Glass Ionomer Cements. Braz Dent J 27(6): 681-687.

21. Brambilla E, Ionescu A, Gagliani M, Cochis A, Arciola CR, et al. (2012) Biofilm Formation on Composite Resins for Dental Restorations: An in situ Study on the Effect of Chlorhexidine Mouthrinses. Int J Artif Organs 35(10): 792-799. 
This work is licensed under Creative Commons Attribution 4.0 License

DOI:_10.19080/ADOH.2018.08.555736
Your next submission with Juniper Publishers will reach you the below assets

- Quality Editorial service

- Swift Peer Review

- Reprints availability

- E-prints Service

- Manuscript Podcast for convenient understanding

- Global attainment for your research

- Manuscript accessibility in different formats ( Pdf, E-pub, Full Text, Audio)

- Unceasing customer service

Track the below URL for one-step submission https://juniperpublishers.com/online-submission.php 